\title{
Off-pump versus on-pump coronary artery bypass grafting: Insights from the Arterial Revascularization Trial
}

\author{
Umberto Benedetto, MD, PhD, ${ }^{a}$ Douglas G. Altman, DSc, ${ }^{b}$ Stephen Gerry, MSc, ${ }^{\mathrm{b}}$ Alastair Gray, PhD, \\ Belinda Lees, BSc, PhD, ${ }^{\mathrm{d}}$ Marcus Flather, $\mathrm{MD},{ }^{\mathrm{e}}$ and David P. Taggart, MD, PhD, ${ }^{\mathrm{d}}$ on behalf of the Arterial \\ Revascularization Trial investigators
}

\begin{abstract}
Background: The long-term effects of off-pump coronary artery bypass continue to be controversial because some studies have reported increased adverse event rates with off-pump coronary artery bypass when compared with on-pump coronary artery bypass. The Arterial Revascularization Trial compared survival after bilateral versus single internal thoracic artery grafting. The choice of off-pump coronary artery bypass versus on-pump coronary artery bypass was based on the surgeon's discretion. We performed a post hoc analysis of the Arterial Revascularization Trial to compare 5-year outcomes with 2 strategies.
\end{abstract}

Methods: Among 3102 patients enrolled in the Arterial Revascularization Trial, we selected 1260 patients who underwent off-pump coronary artery bypass versus 1700 patients who underwent on-pump coronary artery bypass with cardioplegic arrest for the present comparison. Primary outcomes were 5-year mortality and incidence of major cardiac and cerebrovascular events, including cardiovascular death, myocardial infarction, cerebrovascular accident, and revascularization after index procedure. Propensity score matching selected 1260 pairs for final comparison. Stratified Cox models were used for treatment effect estimate.

Results: Hospital mortality was comparable between off-pump coronary artery bypass and on-pump coronary artery bypass groups (12 [1.0\%] vs $15[1.2 \%]$; $P=.7)$. Conversion rate to on-pump during off-pump coronary artery bypass was 29 of $1260(2.3 \%)$. When compared with off-pump coronary artery bypass not converted, off-pump coronary artery bypass converted to on-pump presented a remarkably higher hospital mortality $(10.3 \%$ vs $0.7 \% ; P<.001)$. At 5 years, the mortality rate was $110(8.9 \%)$ versus $102(8.3 \%)$ in the off-pump coronary artery bypass and on-pump coronary artery bypass groups, respectively, with no significant difference (hazard ratio, 1.14; 95\% confidence interval, $0.86-1.52 ; P=.35$ ). Incidence of major cardiac and cerebrovascular events was 175 (14.3) versus 169 (13.8) in the off-pump coronary artery bypass and on-pump coronary artery bypass groups, respectively, with no significant difference (hazard ratio, 1.05; $95 \%$ confidence interval, $0.84-1.31 ; P=.65$ ).

Conclusions: The present post hoc Arterial Revascularization Trial analysis supports the hypothesis that both off-pump coronary artery bypass and on-pump coronary artery bypass are equally effective and safe. (J Thorac Cardiovasc Surg 2018;155:1545-53)

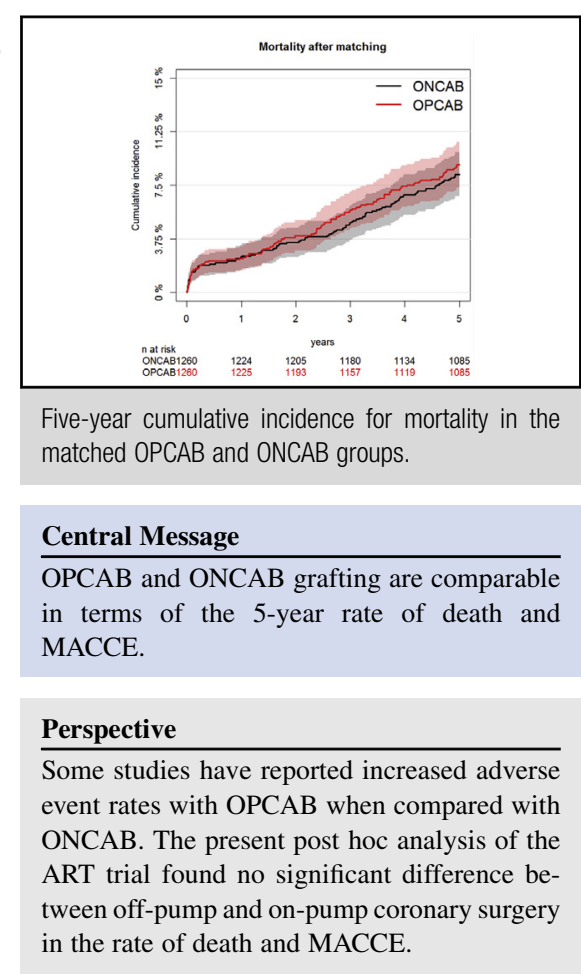

See Editorial Commentary page 1554.

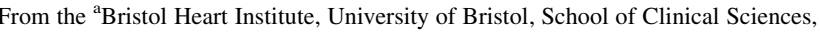
United Kingdom; ${ }^{b}$ Centre for Statistics in Medicine, Nuffield Department of Orthopaedics, Rheumatology, and Musculoskeletal Sciences, ${ }^{\mathrm{c} D e p a r t m e n t}$ of Public Health, Health Economics Research Centre, University of Oxford, Oxford, United

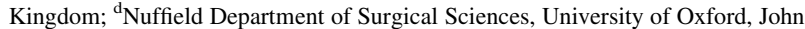
Radcliffe Hospital, Oxford, United Kingdom; and ${ }^{\mathrm{e}}$ Research and Development Unit, Norfolk and Norwich University Hospitals NHS Foundation Trust, Norwich, United Kingdom.

Read at the 97th Annual Meeting of The American Association for Thoracic Surgery, Boston, Massachusetts, April 29-May 3, 2017.
}

Received for publication Feb 16, 2017; revisions received Sept 7, 2017; accepted for publication Oct 16, 2017; available ahead of print Jan 20, 2018.

Address for reprints: Umberto Benedetto, $\mathrm{MD}, \mathrm{PhD}$, Bristol Heart Institute, University of Bristol, Senate House, Tyndall Ave, Bristol BS8 1TH, United Kingdom (E-mail: Umberto.benedetto@ hotmail.com).

0022-5223/\$36.00

Copyright (C) 2017 by The American Association for Thoracic Surgery https://doi.org/10.1016/j.jtcvs.2017.10.135 


\section{Abbreviations and Acronyms \\ ART $=$ Arterial Revascularization Trial \\ CI $\quad=$ confidence interval \\ CORONARY $=$ CABG Off or On Pump \\ Revascularization Study \\ CVA $=$ cerebrovascular accident \\ MACCE = major cardiac and cerebrovascular events \\ MI $=$ myocardial infarction \\ ONCAB = on-pump coronary artery bypass \\ OPCAB = off-pump coronary artery bypass \\ ROOBY $=$ Randomized On/Off Bypass}

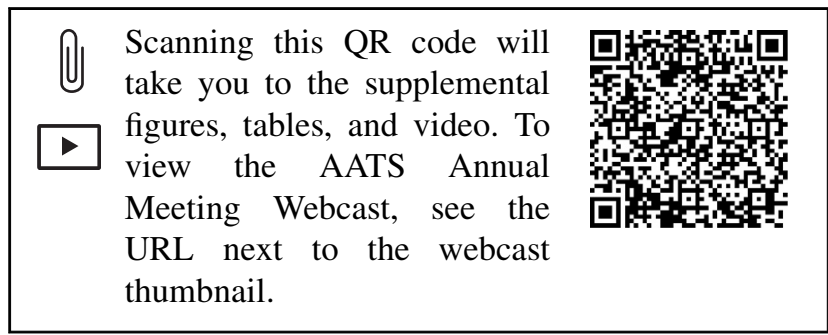

Despite the potential advantages of avoiding cardiopulmonary bypass, the postulated benefits of off-pump coronary artery bypass $(\mathrm{OPCAB})$ in terms of perioperative mortality and morbidity including stroke were not realized in the majority of studies comparing the 2 strategies. ${ }^{1}$ Furthermore, the long-term effects of OPCAB continue to be controversial. The increased technical complexity of OPCAB can result in less complete revascularization and reduced graft patency rates, with some studies reporting increased adverse event rates with $\mathrm{OPCAB}$ when compared with on-pump coronary artery bypass (ONCAB).$^{2-5}$

Two large randomized controlled trials comparing OP$\mathrm{CAB}$ with $\mathrm{ONCAB}$ have recently reported conflicting findings. The CABG Off or On Pump Revascularization Study $(\text { CORONARY })^{6}$ has recently shown comparable 5-year results between the 2 techniques. However, CORONARY enrolled only higher-risk patients, and this aspect may limit the generalizability of the study findings. On the other hand, the Department of Veterans Affairs Randomized On/Off Bypass (ROOBY) Trial ${ }^{7}$ has reported increased 5-year mortality with OPCAB. However, the ROOBY trial was criticized for the fact that the conversion rate to cardiopulmonary bypass was unacceptably high at $12 \%$, and this brought some skepticism on the level of "offpump" experience of the surgeons involved in the study.

Consequently, the question whether OPCAB increases the risk of adverse events over the longer term when compared with ONCAB continues. The Arterial Revascularization Trial (ART) is designed to compare 10-year survival after bilateral internal thoracic artery versus single left internal thoracic artery grafting, and an interim report at 5 years has not shown any clear difference between the 2 groups. ${ }^{8}$ In the ART, the choice of OPCAB versus ON$\mathrm{CAB}$ was based on the surgeon's discretion. We sought to achieve further insights into the comparison between the 2 strategies by performing a post hoc analysis of the ART.

\section{MATERIALS AND METHODS}

The present study is a post hoc retrospective analysis of 5-year outcomes of the ART trial. This research adheres to the principles set forth in the Declaration of Helsinki (http://www.wma.net/en/30publications/ 10policies/b3/index.html). In the ART, the choice of OPCAB versus ON$\mathrm{CAB}$ was based on the surgeon's discretion. OPCAB versus ONCAB strategy adopted was available for all patients enrolled. Among patients enrolled in the ART $(n=3102)$ from 2004 to 2007, we excluded those who did not undergo surgery $(\mathrm{n}=23)$. In 2 cases, there was no information regarding the use of cardiopulmonary bypass. We also excluded patients who received on-pump beating heart surgery $(n=19)$ and 95 patients who received crossclamp fibrillation. The present analysis compared 1260 patients who underwent $\mathrm{OPCAB}$ versus 1700 patients who underwent $\mathrm{ONCAB}$ with cardioplegic arrest. OPCAB cases requiring intraoperative conversion to on-pump were included in the OPCAB group in the primary analysis (Figure 1). A total of 156 surgeons were involved. For 134 patients (60 OPCAB, $74 \mathrm{ONCAB}$ ), no information on participating surgeon was available. The total number of procedures performed by each surgeon and the choice between $\mathrm{OPCAB}$ versus ONCAB presented a large variation with a large proportion of surgeons performing only a few procedures (Table E1). No information was available on individual surgeon practice pattern and OPCAB experience before they took part in the trial (ie, the number of $\mathrm{OPCAB}$ vs ONCAB procedures performed per year).

\section{Trial Design}

The ART has been approved by the institutional review board of all participating centers, and informed consent was obtained from each participant. The protocol for the ART has been published. ${ }^{9}$ Briefly, the ART is a 2 -arm, randomized multicenter trial conducted in 28 hospitals in 7 countries, with patients being randomized equally to single internal thoracic artery or bilateral internal thoracic artery grafts. Eligible patients were those with multivessel coronary artery disease undergoing coronary artery bypass grafting, including patients requiring urgent treatment. Only patients requiring emergency treatment (refractory myocardial ischemia/ cardiogenic shock) and patients requiring single grafts or redo surgery were excluded.

\section{Follow-up}

Questionnaires were sent to study participants by mail at 12 months and then every year after surgery. No clinic visits were planned apart from the routine clinical 6-week postoperative visit. Participants were sent stamped addressed envelopes to improve the return rates of postal questionnaires. Study coordinators contacted participants by telephone to alert them to the questionnaire's arrival and to ask them about medications, adverse events, and health services resource use. Mean follow-up time for the present analysis was $4.9 \pm 1.0$ years. Follow-up at 5 years was completed for 2833 of 2960 patients $(96 \%)$.

\section{Study Outcomes}

The 2 strategies were compared in terms of hospital outcomes, 5-year mortality, and incidence of major cardiac and cerebrovascular events 


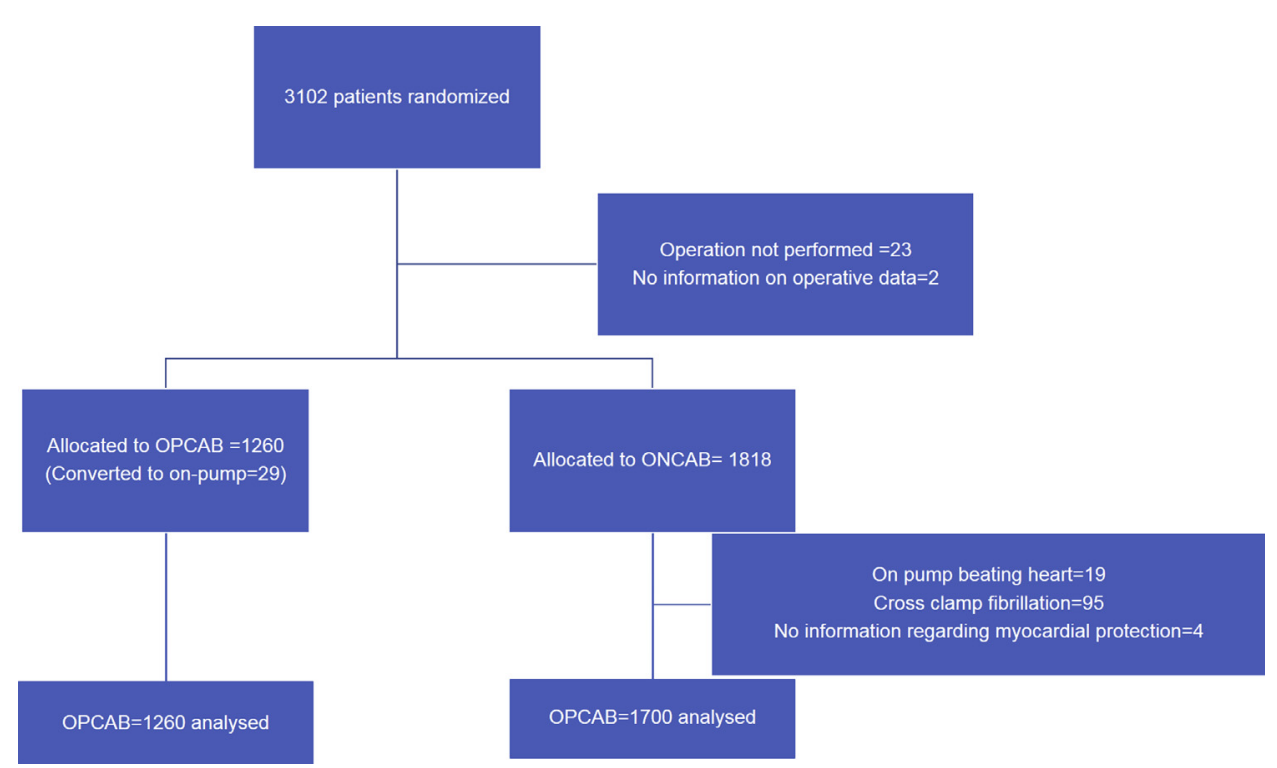

FIGURE 1. Study flow chart for patient inclusion/exclusion. $O P C A B$, Off-pump coronary artery bypass; $O N C A B$, on-pump coronary artery bypass.

(MACCE), which included cardiovascular death, nonfatal myocardial infarction (MI), nonfatal cerebrovascular accident (CVA), and repeat revascularization. Treatment effect on individual MACCE components was also investigated. Adverse events were adjudicated blind to surgical procedure by a member of the Clinical Event Review Committee.

\section{Outcomes Definitions}

Death was classified into cardiovascular and noncardiovascular, when possible, using autopsy reports and death certificates. Congestive heart failure, arrhythmia or MI, pulmonary embolus, and dissection were considered cardiovascular causes of death.

MI was diagnosed when 2 of the following 3 criteria were present: (1) unequivocal electrocardiogram changes; (2) elevation of cardiac enzyme(s) above twice the upper limit of normal or diagnostic troponin increases; and (3) chest pain typical for acute MI that lasted more than 20 minutes. CVA was defined as new neurologic deficit evidenced by clinical signs of paresis, plegia, or new cognitive dysfunction including any mental status alteration lasting more than 24 hours or evidence on computed tomography or magnetic resonance imaging scan of recent brain infarct ( $<6$ months). Repeat revascularization was defined as coronary bypass surgery or percutaneous coronary intervention performed after trial procedure. Acute kidney injury was defined as a $0.3 \mathrm{mg} / \mathrm{dL}(\geq 26.5 \mathrm{mmol} / \mathrm{L})$ creatinine increase from baseline within 48 hours of surgery.

\section{Statistical Analysis}

Multiple imputation $(m=3)$ was used to address missing data. Rubin's method ${ }^{10}$ was used to combine results from each of the imputed data sets (Amelia $\mathrm{R}$ package). Because of the lack of randomization with regard to receiving $\mathrm{OPCAB}$, a propensity score was generated for each patient from a multivariable logistic regression model based on 23 pretreatment covariates as independent variables with $\mathrm{OPCAB}$ versus $\mathrm{ONCAB}$ as a binary dependent variable. ${ }^{10}$ Pairs of patients were derived using greedy $1: 1$ matching with a caliper of width of 0.2 standard deviation of the logit of the propensity score (nonrandom R package). The quality of the match was assessed by comparing selected pretreatment variables in propensity scorematched patients using the standardized mean difference, with an absolute standardized difference of greater than $10 \%$ taken to represent meaningful covariate imbalance. ${ }^{11}$ McNemar's test and paired $t$ test were used to assess the statistical significance of the risk difference for hospital outcomes. ${ }^{12}$ Cox regression models stratified on the matched pairs ${ }^{12}$ were used to estimate the treatment effect on 5-year outcomes. This approach accounts for the within-pair homogeneity by allowing the baseline hazard function to vary across matched sets. Risk competing framework was used to estimate the treatment effect on MACCE individual components. The Schoenfeld residuals test was used to test the independence between residuals and time, and thus to test the proportional hazards assumption in Cox models (survival $\mathrm{R}$ package).

Because of the large number of participating surgeons and the marked variability of total number of procedures and OPCAB procedures performed individually, performing surgeons could not be included in the propensity score model. To account for the potential influence of individual surgeon's $\mathrm{OPCAB}$ experience, we classified each patient according to quartiles of total number of OPCAB procedures performed in the trial by the relative surgeon (0 [on-pump only], 1-5 [small OPCAB volume], 6-60 [moderate $\mathrm{OPCAB}$ volume], $>60$ [high $\mathrm{OPCAB}$ volume]), and outcomes in the matched sample were reported accordingly for descriptive purpose. Finally, baseline characteristics and outcomes between OPCAB cases converted to on pump versus not converted were also reported. All statistical analysis was performed using R Statistical Software (version 3.2.3; R Foundation for Statistical Computing, Vienna, Austria).

\section{RESULTS}

\section{Patients' Characteristics and Operative Data}

The OPCAB group was more likely to have higher creatinine and to receive a bilateral internal thoracic artery graft, and was less likely to have treated hypertension, to have a history of smoking, and to receive saphenous vein grafts. The total number of grafts per patient was comparable in the $\mathrm{OPCAB}$ and $\mathrm{ONCAB}$ groups $(3.20 \pm 0.97$ vs $3.19 \pm 0.76 ; P=.7)$. However, in the OPCAB group, the right coronary artery was less likely to be revascularized $(62.1 \%$ vs $73.4 \% ; P<.001)$, whereas diagonal branches were more likely to be grafted in the OPCAB group $(35.7 \%$ vs $29.2 \% ; P<.001)$. The 2 groups did not differ 
in the rate of left anterior descending artery grafting $(98.1 \%$ vs $98.7 \% ; P=.24)$ and circumflex artery grafting $(91.8 \%$ vs $92.6 \% ; P=.45$ ).

Propensity score matching selected 1260 matched pairs for final comparison $(\mathrm{C}$ statistic $=0.71)($ Figure E1). No residual imbalance was observed between matched groups (all standardized mean difference $<10 \%$ ) (Table 1 and Figure E2). After matching, the number of grafts in the OP$\mathrm{CAB}$ and $\mathrm{ONCAB}$ groups was comparable $(3.20 \pm 0.97 \mathrm{vs}$ $3.17 \pm 0.87 ; P=.35)$.

\section{Hospital Outcomes}

Hospital outcome comparisons before and after matching are shown in Table 2. In-hospital mortality was low and comparable between $\mathrm{OPCAB}$ and ONCAB groups $(1.0 \%$ vs $1.2 \% P=.70)$. OPCAB was associated with a lower creatine kinase MB peak at 24 hours postoperatively and a relatively lower incidence of MI. However, the rate of intra-aortic balloon pump requirement was comparable between the 2 groups. OPCAB was associated with a lower rate of red blood cell transfusion and

TABLE 1. Baseline characteristics of patients undergoing off-pump coronary artery bypass versus on-pump coronary artery bypass

\begin{tabular}{|c|c|c|c|c|c|}
\hline & OPCAB & ONCAB unmatched & SMD before PSM & ONCAB matched & SMD after PSM \\
\hline $\mathrm{n}$ & 1260 & 1700 & & 1260 & \\
\hline Age $(y)$ mean $(S D)$ & $64(9)$ & $64(9)$ & 1 & $64(9)$ & 1 \\
\hline Female n $(\%)$ & $180(14.3)$ & $240(14.1)$ & 0 & $180(14.3)$ & 0 \\
\hline BMI mean (SD) & $28.10(4.10)$ & $28.28(3.87)$ & 5 & $28.13(3.87)$ & 1 \\
\hline $\mathrm{SBP}(\mathrm{mm} \mathrm{Hg})$ mean (SD) & $133(19)$ & $131(17)$ & 9 & $132.30(18)$ & 2 \\
\hline DBP (mm Hg) mean (SD) & $75(11)$ & $75(11)$ & 5 & $75.24(11.32)$ & -1 \\
\hline Creatinine $(\mathrm{mmol} / \mathrm{L})$ mean $(\mathrm{SD})$ & $100(23)$ & $94(21)$ & 26 & $97.75(21.58)$ & 9 \\
\hline Treated hypertension, n (\%) & $943(75)$ & $1360(80.0)$ & -12 & $950(75.4)$ & -1 \\
\hline Treated hyperlipemia, n (\%) & $1176(93.3)$ & $1601(94.2)$ & -4 & $1178(93.5)$ & -1 \\
\hline Diabetes, n (\%) & & & -6 & & 1 \\
\hline No & $980(77.8)$ & $1286(75.6)$ & & $983(78.0)$ & \\
\hline Insulin dependent & $70(5.6)$ & $93(5.5)$ & & $67(5.3)$ & \\
\hline Noninsulin dependent & $210(16.7)$ & $321(18.9)$ & & $210(16.7)$ & \\
\hline Smoking, $\mathrm{n}(\%)$ & & & -14 & & -9 \\
\hline Current & $180(14.3)$ & $242(14.2)$ & & $149(11.8)$ & \\
\hline Ex-smoker & $664(52.7)$ & $999(58.8)$ & & $723(57.4)$ & \\
\hline Never & $416(33.0)$ & $459(27.0)$ & & $388(30.8)$ & \\
\hline COPD, n $(\%)$ & $29(2.3)$ & $43(2.5)$ & -2 & $28(2.2)$ & 1 \\
\hline Asthma, n (\%) & $63(5.0)$ & $65(3.8)$ & 6 & $59(4.7)$ & 2 \\
\hline PVD, n (\%) & $90(7.1)$ & $120(7.1)$ & 0 & $81(6.4)$ & 3 \\
\hline TIA, n (\%) & $40(3.2)$ & $60(3.5)$ & -2 & $40(3.2)$ & 0 \\
\hline CVA, n $(\%)$ & $40(3.2)$ & $46(2.7)$ & 3 & $38(3.0)$ & 1 \\
\hline MI, n (\%) & $510(40.5)$ & $726(42.7)$ & -5 & $513(40.7)$ & -1 \\
\hline PCI, n (\%) & $208(16.5)$ & $270(15.9)$ & 2 & $214(17.0)$ & -1 \\
\hline Preoperative AF, n (\%) & $19(1.5)$ & $24(1.4)$ & 1 & $16(1.3)$ & 2 \\
\hline Preoperative LVEF (\%) & & & 5 & & 2 \\
\hline$\geq 50 \%($ good $)$ & $950(75.4)$ & $1289(75.8)$ & & $939(74.5)$ & \\
\hline $31 \%-49 \%$ (moderate) & $268(21.3)$ & $389(22.9)$ & & $303(24.0)$ & \\
\hline$\leq 30 \%$ (poor) & $42(3.3)$ & $22(1.3)$ & & $18(1.4)$ & \\
\hline LMD, n (\%) & $282(22.4)$ & $356(20.9)$ & 4 & $277(22.0)$ & 1 \\
\hline $\mathrm{RA}, \mathrm{n}(\%)$ & $240(19.0)$ & $381(22.4)$ & -8 & $252(20.0)$ & -2 \\
\hline SVG, n (\%) & $936(74.3)$ & $1344(79.1)$ & -11 & 956 (75.9) & -4 \\
\hline BITA, n (\%) & $598(47.5)$ & $691(40.6)$ & 14 & $575(45.6)$ & 4 \\
\hline
\end{tabular}


TABLE 2. Hospital outcomes of patients undergoing off-pump coronary artery bypass versus on-pump coronary artery bypass in the Arterial Revascularization Trial

\begin{tabular}{|c|c|c|c|c|c|}
\hline & ОРСАВ & ONCAB unmatched & $P$ value before PSM* & ONCAB matched & $P$ value after PSM \\
\hline $\mathrm{n}$ & 1260 & 1700 & & 1260 & \\
\hline Death, n (\%) & $12(1.0)$ & $18(1.1)$ & .92 & $15(1.2)$ & .70 \\
\hline CVA, n $(\%)$ & $20(1.6)$ & $19(1.1)$ & .34 & $13(1.0)$ & .29 \\
\hline Perioperative MI, n (\%) & $10(0.8)$ & $40(2.4)$ & .002 & $32(2.5)$ & .001 \\
\hline CK-MB $24 \mathrm{~h}(\mathrm{U} / \mathrm{L})$ mean (SD) & $34(179)$ & $80(125)$ & .007 & 83 (139) & .02 \\
\hline IABP insertion, $\mathrm{n}(\%)$ & $58(4.6)$ & $59(3.5)$ & .14 & $46(3.7)$ & .27 \\
\hline Repeat revascularization, $\mathrm{n}(\%)$ & $8(0.6)$ & $7(0.4)$ & .56 & $7(0.6)$ & 1 \\
\hline POAF, n (\%) & $279(22.1)$ & $451(26.5)$ & .007 & $333(26.4)$ & .01 \\
\hline Renal replacement therapy, n (\%) & $72(5.7)$ & $79(4.6)$ & .22 & $64(5.1)$ & .54 \\
\hline AKI, n (\%) & $225(17.9)$ & $290(17.1)$ & .61 & $221(17.5)$ & .88 \\
\hline Sternal wound complication, $\mathrm{n}(\%)$ & $35(2.8)$ & $67(3.9)$ & .11 & $52(4.1)$ & .08 \\
\hline Reexploration for bleeding, $\mathrm{n}(\%)$ & $40(3.2)$ & $62(3.6)$ & .55 & $51(4.0)$ & .29 \\
\hline $\mathrm{RBC}$ transfusion, $\mathrm{n}(\%)$ & $165(13.1)$ & $280(16.5)$ & .01 & $207(16.4)$ & .02 \\
\hline
\end{tabular}

$O P C A B$, Off-pump coronary artery bypass; $O N C A B$, on-pump coronary artery bypass; $P S M$, propensity score matching; $C V A$, cerebrovascular accident; $M I$, myocardial infarction; $C K-M B$, creatine kinase-MB; $S D$, standard deviation; $I A B P$, intra-aortic balloon pump; $P O A F$, postoperative atrial fibrillation; $A K I$, acute kidney injury; $R B C$, red blood cell. *Chi-square test or $t$ test. $\dagger \mathrm{McNemar}$ test or paired $t$ test.

a trend toward a lower incidence of sternal wound complication. OPCAB did not reduce the incidence of postoperative CVA, acute kidney injury, and renal replacement therapy.

\section{Five-Year Outcomes}

Five-year outcome comparisons before and after matching are shown in Table 3. Five-year mortality (hazard ratio, 1.14; $95 \%$ confidence interval $[\mathrm{CI}], 0.86-1.52 ; P=.35$ ) (Figure 2) and MACCE risk (hazard ratio, 1.05; 95\% CI, $0.84-1.31 ; P=.65$ ) were comparable between the 2 groups. In terms of individual MACCE components, OPCAB was associated with a marginally nonsignificant $1.1 \%$ absolute risk reduction in MI. Cardiovascular death, CVA, and repeat revascularization rates were comparable between the 2 groups (Figure 3).

\section{Impact of Intraoperative Conversion to On-Pump on Outcomes}

Intraoperative conversion to on-pump occurred in 29 of 1260 OPCAB $(2.3 \%)$ procedures. Notably, the distribution of risk factors between the OPCAB converted to on-pump group and OPCAB not converted group was similar (Table E2). When compared with OPCAB not converted, OPCAB converted to on-pump presented a remarkably higher hospital mortality $(10.3 \%$ vs $0.7 \%$; $P<.001)$ and increased rate of hospital complications despite similar distribution of baseline risk factors. The trend toward poorer outcomes among OPCAB cases converted to on-pump persisted at 5 years (Table E3 and Figure E3).

\section{Surgeon Off-Pump Coronary Artery Bypass Volume and Outcomes}

A total of 95 surgeons performed on-pump only (951 patients); 33 surgeons performed 1 to 5 OPCAB procedures (531 patients; 62 OPCAB; 469 ONCAB); 25 surgeons performed 6 to 60 OPCAB procedures (in total 779 patients; $530 \mathrm{OPCAB} ; 249 \mathrm{ONCAB}$ ); and 3 surgeons performed more than 60 OPCAB procedures (in total 699 patients; 668 OPCAB; 31 ONCAB).

Baseline characteristics and outcomes in the matched $\mathrm{OPCAB}$ and $\mathrm{ONCAB}$ groups stratified per surgeon OP$\mathrm{CAB}$ volume are reported in Tables E4 and E5 and Figure E4. OPCAB cases performed by "sporadic" OP$\mathrm{CAB}$ surgeons (1-5 OPCAB procedures) presented a high rate of conversion $(12.9 \%)$, a lower number of grafts performed $(2.60 \pm 0.88)$, and a higher rate of operative mortality (4.8\%) compared with other OPCAB subgroups despite that distribution of risk factors was similar.

When OPCAB performed by 3 high-volume OPCAB surgeons ( $>60)$ was compared with ONCAB by 95 "on-pump only" surgeons performing on-pump only, we found similar 5 -year overall mortality and MACCE rates.

Among 28 ONCAB cases performed by 3 high-volume OPCAB surgeons $(>60)$, we observed a high hospital mortality rate $(7.1 \%)$. However, this subgroup presented a higher prevalence of important risk factors, including left ventricular ejection fraction less than $30 \%$ and increased creatinine compared with other ONCAB subgroups, suggesting that these 3 surgeons selectively used on-pump for high-risk cases. 
TABLE 3. Five-year outcomes of patients undergoing on-pump coronary artery bypass versus off-pump coronary artery bypass in the Arterial Revascularization Trial (expressed in number of events and cumulative incidence)

\begin{tabular}{|c|c|c|c|c|c|}
\hline & ОРСАВ & ONCAB unmatched & ONCAB matched & HR $(95 \%$ CI $)$ after PSM $*$ & $P$ value after PSM \\
\hline $\mathrm{n}$ & 1260 & 1700 & 1260 & & \\
\hline Mortality, n (\%) & $110(8.9)$ & $134(8.0)$ & $102(8.3)$ & $1.14(0.86-1.52)$ & .35 \\
\hline MACCE, n (\%) & $175(14.3)$ & $217(13.1)$ & $169(13.8)$ & $1.05(0.84-1.31)$ & .65 \\
\hline CV death, $\mathrm{n}(\%)$ & $51(4.1)$ & $47(2.8)$ & $39(3.1)$ & $1.39(0.90-2.13)$ & .13 \\
\hline MI, n (\%) & $37(3.0)$ & $61(3.6)$ & $51(4.1)$ & $0.66(0.43-1.02)$ & .06 \\
\hline CVA, n (\%) & $41(3.3)$ & $42(2.5)$ & $32(2.6)$ & $1.32(0.83-2.11)$ & .24 \\
\hline Revascularization, n (\%) & $90(7.5)$ & $108(6.4)$ & $84(6.8)$ & $1.09(0.80-1.49)$ & .58 \\
\hline
\end{tabular}

$O P C A B$, Off-pump coronary artery bypass; $O N C A B$, on-pump coronary artery bypass; $H R$, hazard ratio; $C I$, confidence interval; $P S M$, propensity score matching; $M A C C E$, major cardiac and cerebrovascular event; $C V$, cardiovascular; $M I$, myocardial infarction; $C V A$, cerebrovascular accident. *Cox model stratified for matched pairs.

\section{DISCUSSION}

The main finding of the present post hoc analysis of the ART showed that when compared with ONCAB, OPCAB was associated with a comparable number of grafts performed, a reduced operative morbidity, and comparable 5-year mortality and incidence of MACCE. Conversion rate to on-pump was relatively low $(2.3 \%)$ but was associated with a remarkable increase in hospital mortality and morbidity and poorer 5-year outcomes.

In the ART, more than $50 \%$ of OPCAB procedures (668/ 1260) were performed by 3 of 156 participating surgeons, whereas 95 surgeons performed on-pump only. OPCAB performed by 3 high-volume OPCAB surgeons was associated with hospital and 5-year mortality comparable to those observed after ONCAB performed by 95 "on-pump only" surgeons.

We found that OPCAB performed by "sporadic" OP$\mathrm{CAB}$ surgeons (1-5 OPCAB procedures) was associated with a marked increase in conversion rate $(12.9 \%)$, a lower number of grafts performed, and increased hospital mortality $(4.8 \%)$.

There is continued debate as to whether OPCAB may affect long-term outcomes because of a lower number of grafts performed and subsequent effect of incomplete revascularization. Takagi and colleagues ${ }^{2}$ pooled 5 randomized controlled trials and 17 adjusted observational studies that had reported long-term ( $\geq 5$-year) all-cause mortality. In observational studies $(102,820$ patients) but not in randomized trials (1486 patients), OPCAB was associated with increased late mortality.

Criticisms for observational studies comparing $\mathrm{OPCAB}$ and $\mathrm{ONCAB}$ include a possible bias toward including higher-risk patients in the OPCAB group. ${ }^{13}$ Furthermore, incomplete revascularization in retrospective studies may be a surrogate marker for higher burden of comorbidities and per se might not be particularly relevant to patients' outcomes. $^{14}$
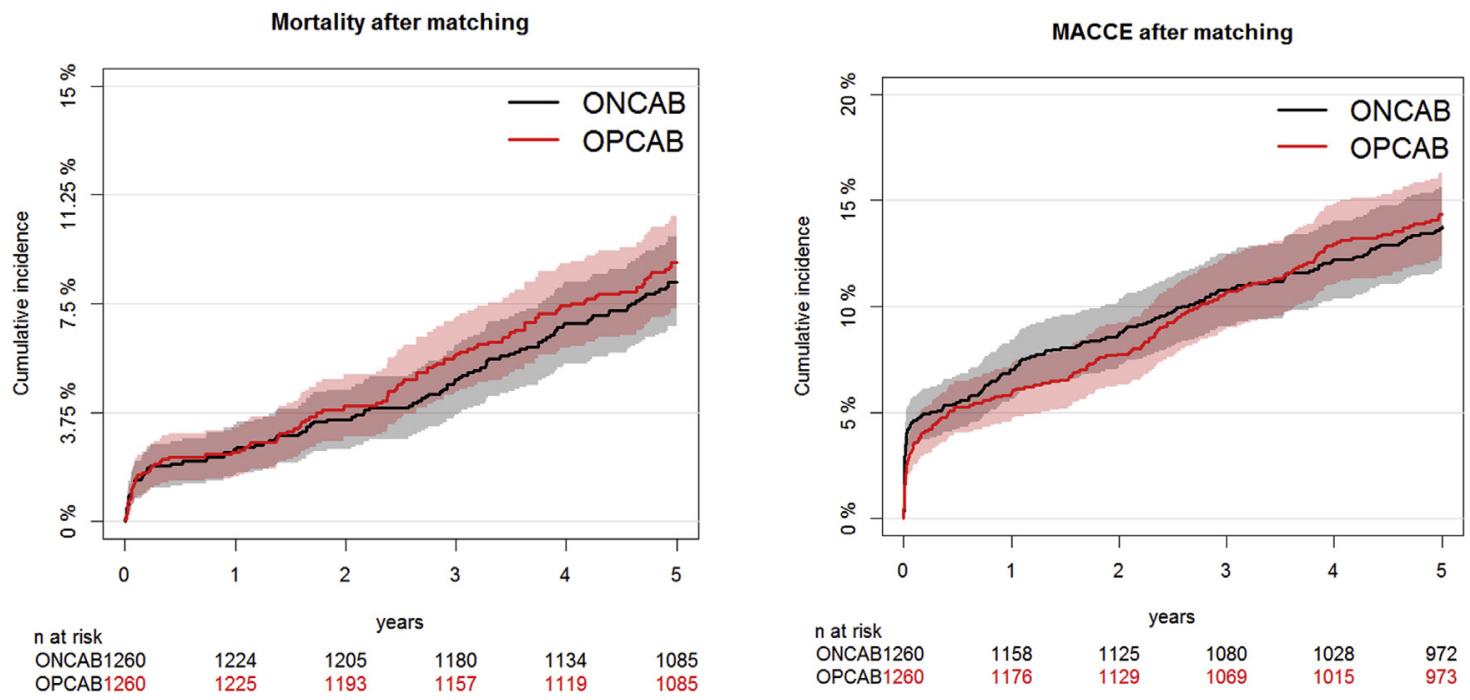

FIGURE 2. Five-year cumulative incidence for mortality and MACCE in the matched OPCAB and ONCAB groups. ONCAB, On-pump coronary artery bypass; $O P C A B$, off-pump coronary artery bypass. 
CV death

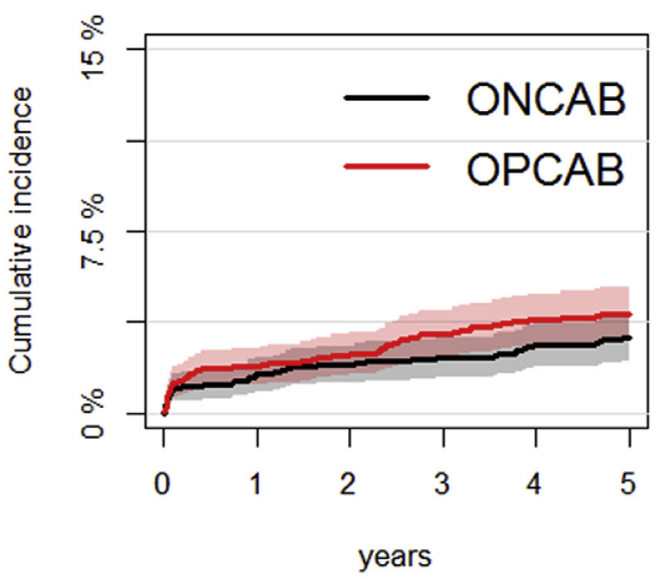

CVA

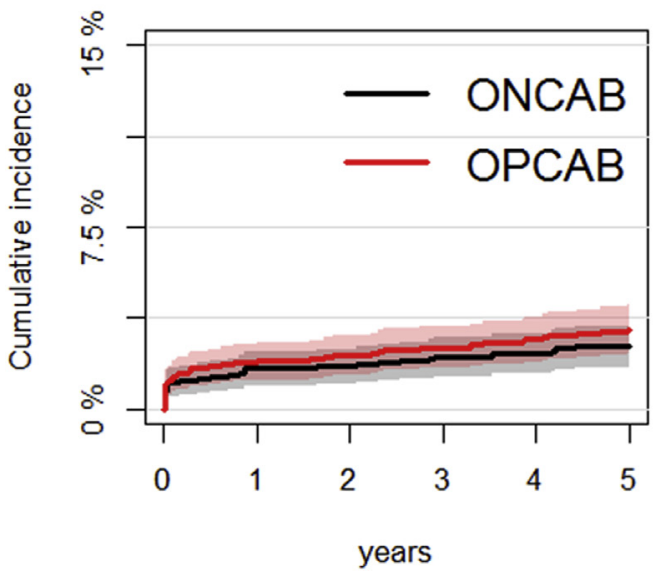

MI

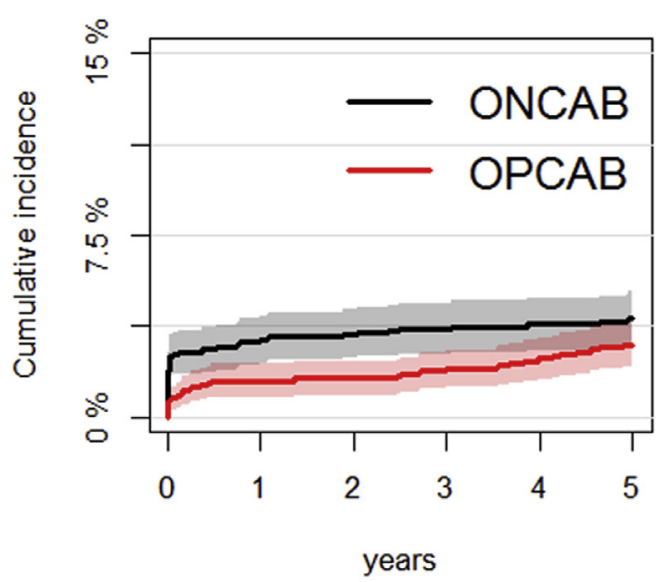

Repeat Revascularization

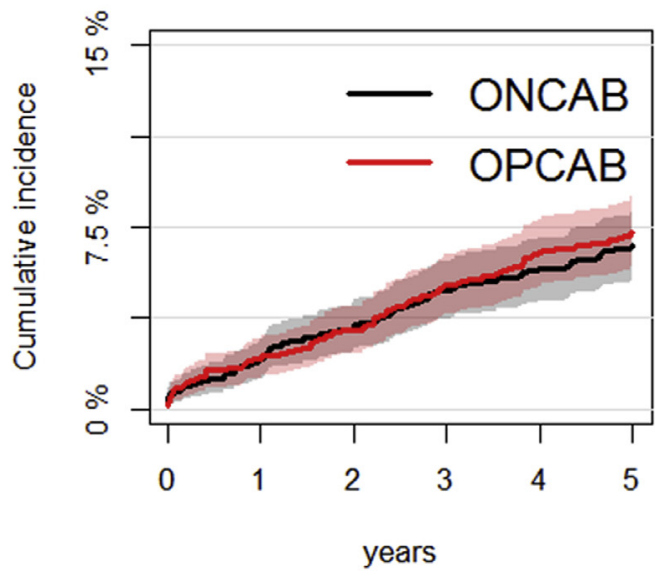

FIGURE 3. Five-year cardiovascular death, MI, CVA, and revascularization cumulative incidence in the OPCAB and ONCAB groups. $C V$, Cardiovascular; $O N C A B$, on-pump coronary artery bypass; $O P C A B$, off-pump coronary artery bypass; $M I$, myocardial infarction; $C V A$, cerebrovascular accident.

The CORONARY trial ${ }^{6}$ is a large trial $(\mathrm{n}=4502$ patients $)$ designed to compare the 2 strategies. The final 5-year results showed similar outcomes with OPCAB and ONCAB. The difference between OPCAB and ONCAB in terms of number of grafts (3.0 vs 3.2) and incidence of incomplete revascularization $(11.8 \%$ vs $10.0 \%)$ were only marginal. In the CORONARY, each procedure was performed by a surgeon who had expertise in the specific type of surgery (completion of $>100$ cases of the specific technique, offpump or on-pump). A limitation of the CORONARY is that only patients at higher risk were enrolled, and this aspect might limit the generalizability of the study findings.

In contrast, in the ROOBY trial, ${ }^{7}$ which enrolled 2203 patients, OPCAB has been recently reported to be associated with increased 5 -year mortality $(15.2 \%$ in the OPCAB group vs $11.9 \%$ in the ONCAB group, relative risk, 1.28 ; $95 \%$ CI, $1.03-1.58 ; P=.02)$ and MACCE rates $(31.0 \%$ in the OPCAB group vs $27.1 \%$ in the ONCAB group; relative risk, $1.14 ; 95 \% \mathrm{CI}, 1.00-1.30 ; P=.046)$. This trial also demonstrated that the patency rate in the off-pump arm was lower than in the on-pump arm at 12-month angiography. ${ }^{15}$ Such findings can be partially explained on the basis that the 53 participating surgeons enrolled on average only 8 patients per year during the study period and had unacceptably high conversion rates to on-pump surgery $(12 \%)$ and incomplete revascularization $(18 \%)$. Moreover, in $60 \%$ of the cases, a resident was the primary surgeon, again raising concerns about the relative inexperience translating into poor graft patency.

The present post hoc analysis supports the equipoise between $\mathrm{OPCAB}$ and $\mathrm{ONCAB}$ in terms of safety and efficacy. We found a trend toward a lower incidence of $\mathrm{MI}$ in the OP$\mathrm{CAB}$ group, mainly related to the early phase. It is well recognized that $\mathrm{OPCAB}$ is associated with a lower release 


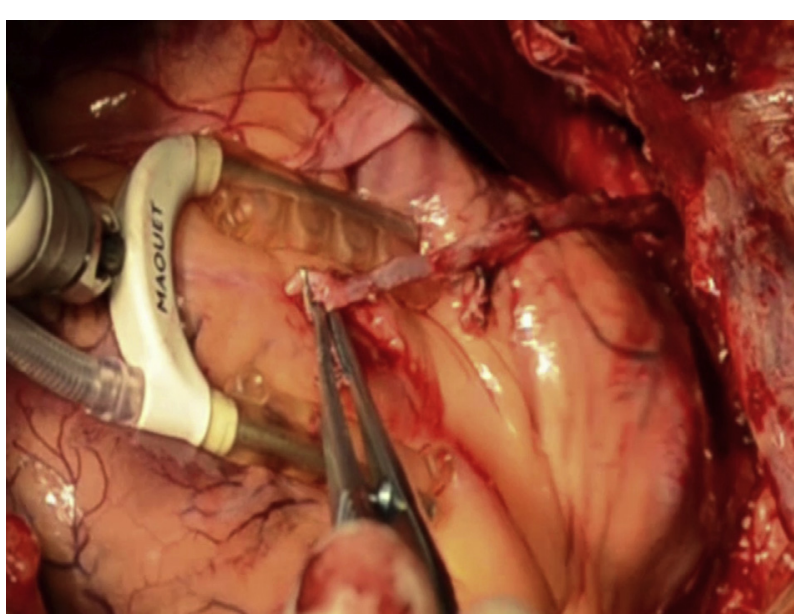

VIDEO 1. Off-pump coronary artery bypass grafting. Video available at: http://www.jtcvsonline.org/article/S0022-5223(17)32725-3/fulltext.

of myocardial enzymes, ${ }^{16}$ but the clinical relevance of this observation remains unclear. Moreover, the definition of perioperative MI after myocardial revascularization remains controversial, as well as its clinical implication. ${ }^{17}$

In the ART, more than $50 \%$ of OPCAB procedures were performed by 3 high-volume OPCAB surgeons only, and this can partially explain the present findings. When OP$\mathrm{CAB}$ was performed by "sporadic" off-pump surgeons, this was associated with a lower number of grafts, higher conversion rate, and higher hospital mortality. This observation supports the central role of surgeon expertise in determining short- and long-term results after off-pump surgery.

The unique technical challenges of OPCAB promote the perception that adoption of this myocardial revascularization strategy may lead to poorer outcomes during each surgeon's "learning curve." ${ }^{18}$ However, the learning curve in off-pump CABG can be safely negotiated with appropriate patient selection, individualized grafting strategy, peer-topeer training of the entire team, and graded clinical experience. Centers with established off-pump training programs have consistently shown that OPCAB can be safely and successfully taught to trainees without jeopardizing outcomes. ${ }^{19}$

In the current era, an increasing number of patients with a high-risk profile are being referred for surgical myocardial revascularization, and off-pump surgery represents an attractive strategy to reduce operative morbidity especially in this subgroup, as recently supported by a large meta-analysis of randomized controlled trials. ${ }^{20}$ Therefore, OPCAB should remain in the armamentarium of cardiac surgeons (Video 1). However, these superior outcomes in high-risk patients can be achieved only if off-pump surgery is offered to high- and low-risk patients alike, and this further emphasizes the need for recognition of off-pump surgery as a subspecialty with structured training program.

\section{Study Limitations}

The present analysis has intrinsic limitations. The main limitation is the retrospective analysis. The propensity technique can adjust only for measurable and included variables, and we cannot exclude a selection bias based on a nonmeasurable "eye-balling," including the quality of the targets. We had no information on specific surgeon offpump expertise, and we used the total number of offpump procedures performed in the ART as a surrogate of off-pump expertise. However, the validity of this approach was further limited by the large variability of the number of procedures performed per surgeon with a large proportion of surgeons performing less than 5 procedures (67 of 156 surgeons). Moreover, we had no information on reasons for preferring off-pump over on-pump and vice versa across surgeon subgroups. Therefore, subgroup analysis based on surgeon OPCAB volume should be considered only as descriptive and hypothesis generating. Despite that the present analysis did not show a significant difference in terms of mortality between the 2 strategies, there is a marginal trend toward an excess of cardiovascular deaths in the OPCAB group (4.1\% vs $3.1 \%)$, and it can be argued that the present analysis is underpowered to demonstrate a significant difference between the 2 groups. However, this difference is irrelevant when all-cause mortality is considered $(8.9 \%$ vs $8.3 \%)$. All-cause death is the most robust and unbiased index in cardiovascular research because no adjudication is required, thus avoiding inaccurate or biased documentation and inconsistency in end point definition.

\section{CONCLUSIONS}

The present post hoc ART analysis found no significant difference at 5 years between OPCAB and ONCAB in the rate of death, nonfatal stroke, nonfatal MI, or subsequent revascularization procedures. Our results indicate that both procedures are equally effective and safe, at least in the medium term.

\section{Webcast}

You can watch a Webcast of this AATS meeting presentation by going to: https://aats.blob.core.windows.net/ media/17AM/2017-05-03/RM302-304/05-03-17_Room 302-304_0906_Benedetto.mp4.

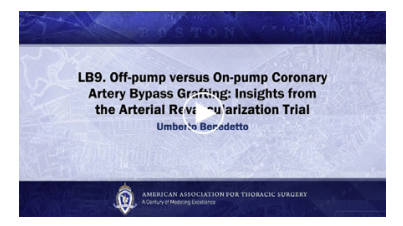




\section{Conflict of Interest Statement}

Authors have nothing to disclose with regard to commercial support.

\section{References}

1. Wijeysundera DN, Beattie WS, Djaiani G, Rao V, Borger MA, Karkouti K, et al. Off-pump coronary artery surgery for reducing mortality and morbidity: metaanalysis of randomized and observational studies. J Am Coll Cardiol. 2005;46: 872-82.

2. Takagi H, Umemoto T; All-Literature Investigation of Cardiovascular Evidence (ALICE) Group. Worse long-term survival after off-pump than on-pump coronary artery bypass grafting. J Thorac Cardiovasc Surg. 2014;148:1820-9.

3. Kim JB, Yun SC, Lim JW, Hwang SK, Jung SH, Song H, et al. Long-term survival following coronary artery bypass grafting: off-pump versus on-pump strategies. J Am Coll Cardiol. 2014;63:2280-8.

4. Bakaeen FG, Chu D, Kelly RF, Ward HB, Jessen ME, Chen GJ, et al. Performing coronary artery bypass grafting off-pump may compromise long-term survival in a veteran population. Ann Thorac Surg. 2013;95:1952-8.

5. Møller CH, Penninga L, Wetterslev J, Steinbrüchel DA, Gluud C. Off-pump versus on-pump coronary artery bypass grafting for ischaemic heart disease. Cochrane Database Syst Rev 2012;3:CD007224.

6. Lamy A, Devereaux PJ, Prabhakaran D, Taggart DP, Hu S, Straka Z, et al. Fiveyear outcomes after off-pump or on-pump coronary-artery bypass grafting. $N$ Engl J Med. 2016;375:2359-68.

7. Shroyer AL, Hattler B, Wagner TH, Collins JF, Baltz JH, Quin JA, et al. Veterans Affairs ROOBY-FS Group. Five-year outcomes after on-pump and off-pump coronary-artery bypass. N Engl J Med. 2017;377:623-32.

8. Taggart DP, Altman DG, Gray AM, Lees B, Gerry S, Benedetto U, et al; ART Investigators. Randomized trial of bilateral versus single internal-thoracicartery grafts. $N$ Engl J Med. 2016;375:2540-9.

9. Taggart DP, Lees B, Gray A, Altman DG, Flather M, Channon K; ART Investigators; Protocol for the Arterial Revascularisation Trial (ART). A randomised trial to compare survival following bilateral versus single internal mammary grafting in coronary revascularisation [ISRCTN46552265]. Trials. 2006;7:7.

10. Rubin DB. Multiple Imputation for Nonresponse in Surveys. New York: J Wiley \& Sons; 1987.

11. Austin PC. A tutorial and case study in propensity score analysis: an application to estimating the effect of in-hospital smoking cessation counseling on mortality. Multivariate Behav Res. 2011;46:119-51.
12. Cohen J. Statistical Power Analysis for the Behavioral Sciences. 2nd ed. Hillsdale, NJ: Lawrence Erlbaum Associates Publishers; 1988.

13. Sellke FW, DiMaio JM, Caplan LR, Ferguson TB, Gardner TJ, Hiratzka LF, et al Comparing on-pump and off-pump coronary artery bypass grafting: numerous studies but few conclusions: a scientific statement from the American Heart Association council on cardiovascular surgery and anesthesia in collaboration with the interdisciplinary working group on quality of care and outcomes research. Circulation. 2005;111:2858-64.

14. Gössl M, Faxon DP, Bell MR, Holmes DR, Gersh BJ. Complete versus incomplete revascularization with coronary artery bypass graft or percutaneous intervention in stable coronary artery disease. Circ Cardiovasc Interv. 2012;5: 597-604.

15. Hattler B, Messenger JC, Shroyer AL, Collins JF, Haugen SJ, Garcia JA, et al Veterans Affairs Randomized On/Off Bypass (ROOBY) Study Group. OffPump coronary artery bypass surgery is associated with worse arterial and saphenous vein graft patency and less effective revascularization: results from the Veterans Affairs Randomized On/Off Bypass (ROOBY) trial. Circulation. 2012 $125: 2827-35$.

16. Chowdhury UK, Malik V, Yadav R, Seth S, Ramakrishnan L, Kalaivani M, et al Myocardial injury in coronary artery bypass grafting: on-pump versus off-pump comparison by measuring high-sensitivity C-reactive protein, cardiac troponin I, heart-type fatty acid-binding protein, creatine kinase-MB, and myoglobin release. J Thorac Cardiovasc Surg. 2008;135:1110-9.

17. Cho MS, Ahn JM, Lee CH, Kang DY, Lee JB, Lee PH, et al. Differential rates and clinical significance of periprocedural myocardial infarction after stenting or bypass surgery for multivessel coronary disease according to various definitions. JACC Cardiovasc Interv. 2017;10:1498-507.

18. Song HK, Petersen RJ, Sharoni E, Guyton RA, Puskas JD. Safe evolution towards routine off-pump coronary artery bypass: negotiating the learning curve. Eur $J$ Cardiothorac Surg. 2003;24:947-52.

19. Murzi M, Caputo M, Aresu G, Duggan S, Angelini GD. Training residents in offpump coronary artery bypass surgery: a 14-year experience. J Thorac Cardiovasc Surg. 2012;143:1247-53.

20. Kowalewski M, Pawliszak W, Malvindi PG, Bokszanski MP, Perlinski D, Raffa GM, et al. Off-pump coronary artery bypass grafting improves short-term outcomes in high-risk patients compared with on-pump coronary artery bypass grafting: meta-analysis. J Thorac Cardiovasc Surg. 2016;151: $60-77$.

Key Words: off-pump coronary artery bypass grafting, survival, propensity score matching 

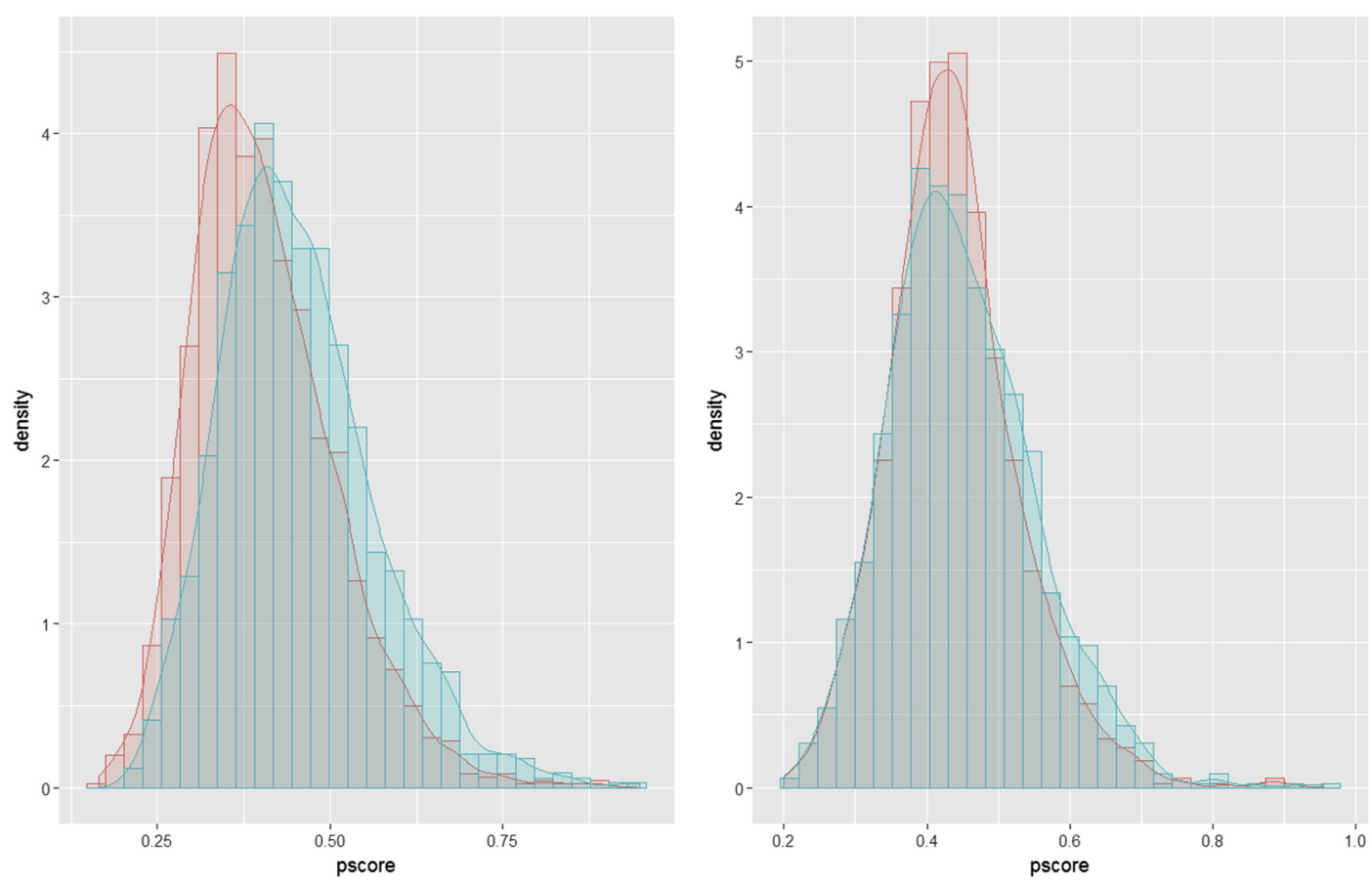

On-pump

Off-pump

FIGURE E1. Propensity score density before and after matching.

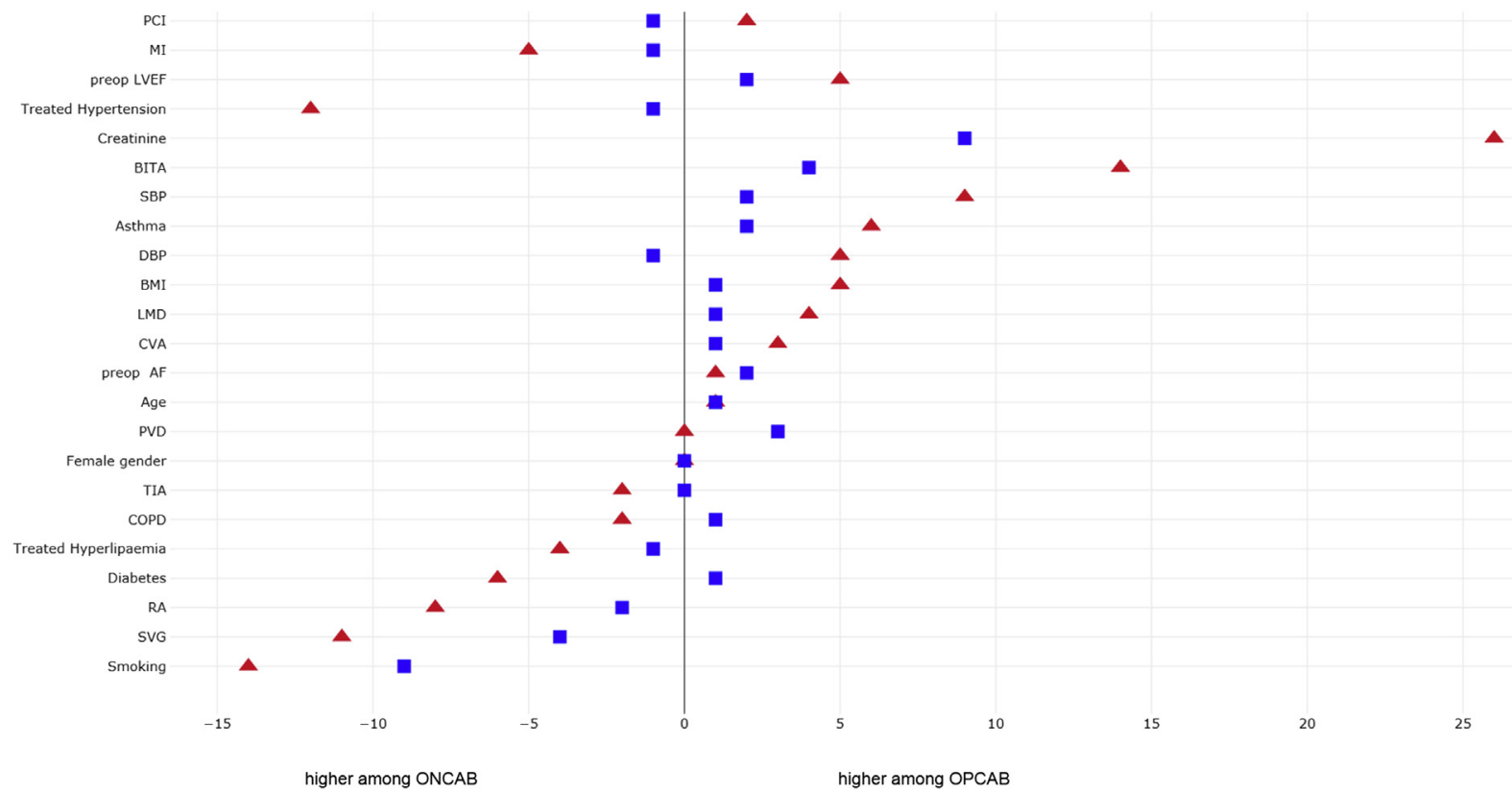

FIGURE E2. Changes in standardized mean difference for baseline characteristics between OPCAB and ONCAB before (red) and after matching (blue). $O N C A B$, On-pump coronary artery bypass; $O P C A B$, off-pump coronary artery bypass; $P C I$, percutaneous coronary intervention; $M I$, myocardial infarction; $L V E F$, left ventricular ejection fraction; $B I T A$, bilateral internal thoracic artery; $S B P$, systolic blood pressure; $D B P$, diastolic blood pressure; $B M I$, body mass index; $L M D$, left main disease; $C V A$, cerebrovascular accident; $A F$, atrial fibrillation; $P V D$, peripheral vascular disease; TIA, transient ischemic attack; $C O P D$, chronic obstructive pulmonary disease; $R A$, radial artery; $S V G$, saphenous vein graft. 

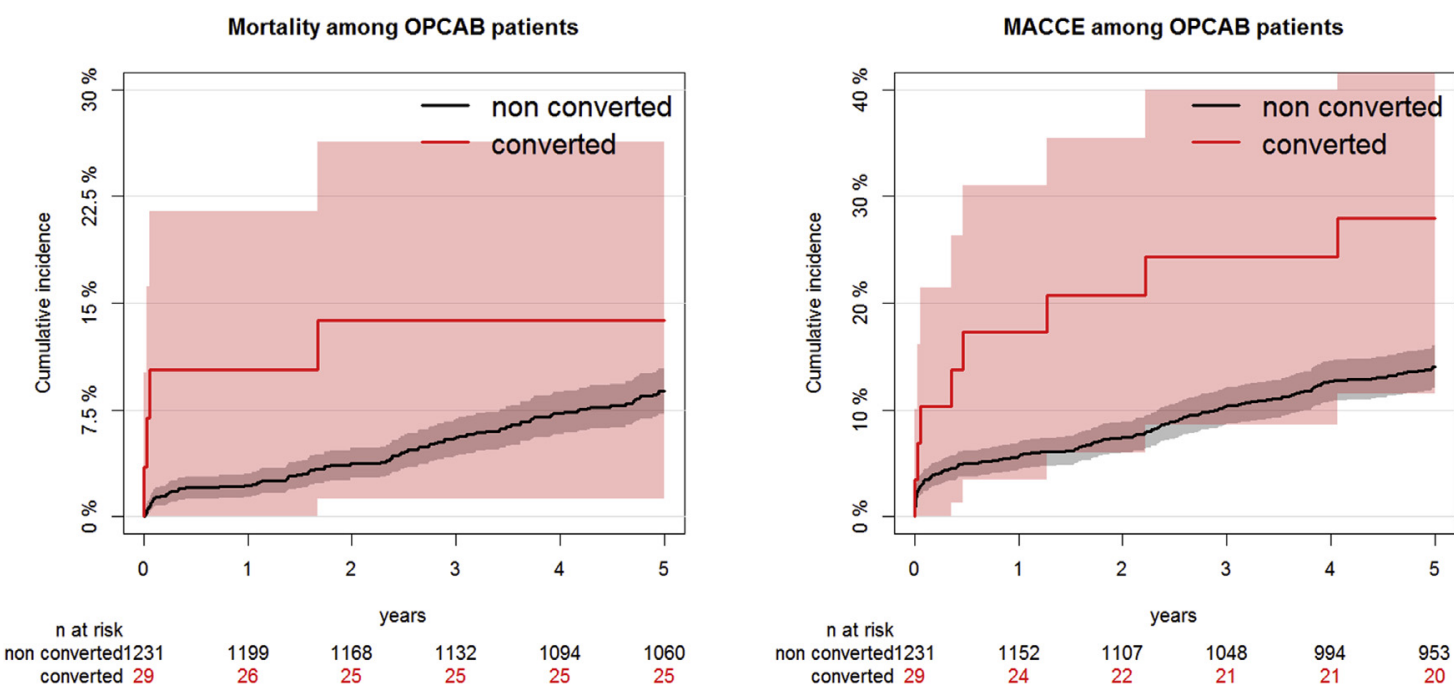

FIGURE E3. Five-year cumulative incidence for mortality and MACCE in the OPCAB group according to the incidence of conversion to on-pump. $O P$ $C A B$, Off-pump coronary artery bypass; $M A C C E$, major cardiac and cerebrovascular event.
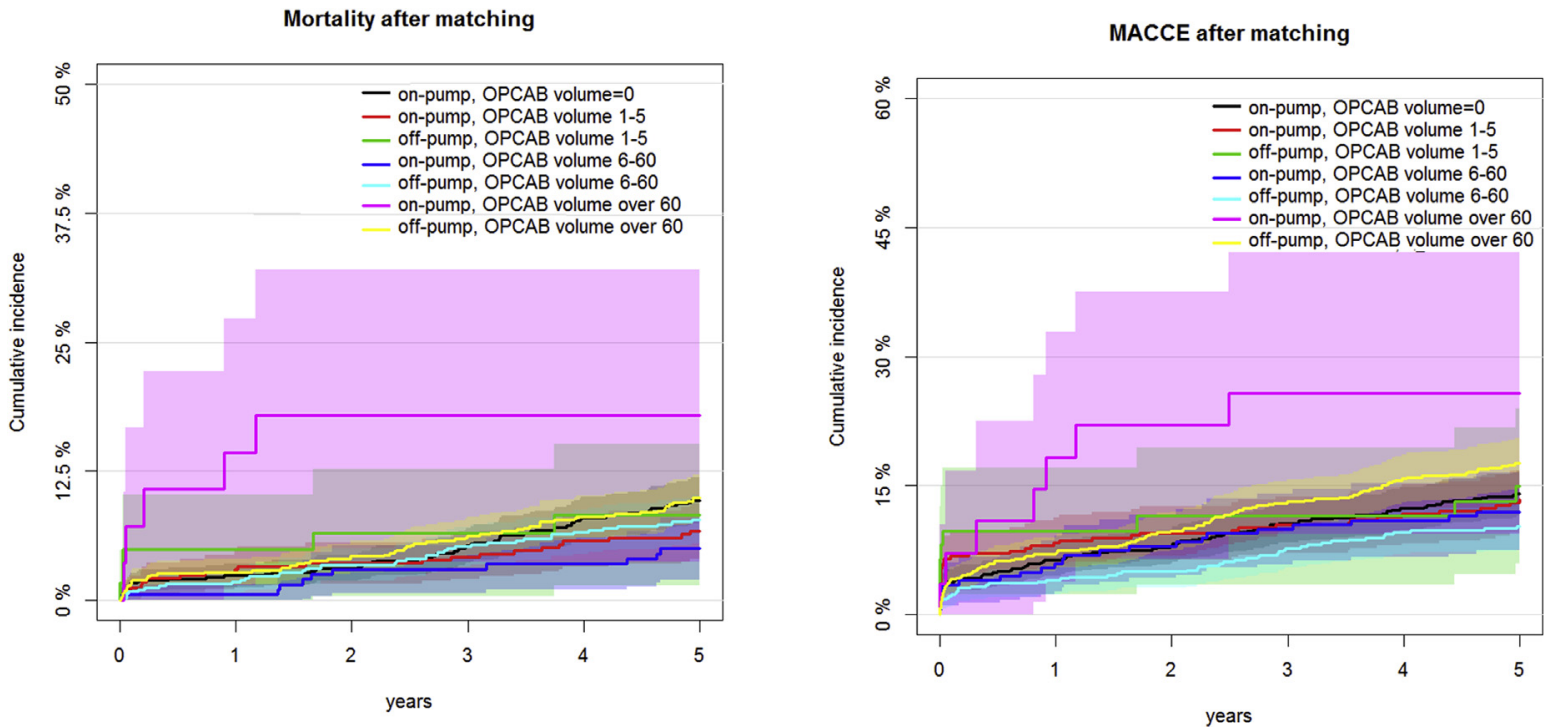

FIGURE E4. Five-year cumulative incidence for mortality and MACCE in the OPCAB and ONCAB groups according to surgeon trial OPCAB volume $(0=$ performing on-pump only; $1-5=$ low OPCAB volume; $6-60=$ moderate volume; $>60=$ high volume $) . O P C A B$, Off-pump coronary artery bypass; $M A C C E$, major cardiac and cerebrovascular event. 
TABLE E1. Off-pump coronary artery bypass, on-pump coronary artery bypass, and total number of cases performed according to individual surgeon

\begin{tabular}{|c|c|c|c|}
\hline Surgeon no. & ONCAB & ОРСАВ & Total \\
\hline Not available & 74 & 60 & 134 \\
\hline 1 & 4 & 0 & 4 \\
\hline 2 & 0 & 1 & 1 \\
\hline 3 & 0 & 2 & 2 \\
\hline 4 & 0 & 2 & 2 \\
\hline 5 & 1 & 5 & 6 \\
\hline 6 & 1 & 0 & 1 \\
\hline 7 & 26 & 0 & 26 \\
\hline 8 & 18 & 0 & 18 \\
\hline 9 & 1 & 10 & 11 \\
\hline 10 & 0 & 1 & 1 \\
\hline 11 & 1 & 0 & 1 \\
\hline 12 & 16 & 0 & 16 \\
\hline 13 & 1 & 0 & 1 \\
\hline 14 & 1 & 1 & 2 \\
\hline 15 & 1 & 0 & 1 \\
\hline 16 & 4 & 0 & 4 \\
\hline 17 & 2 & 0 & 2 \\
\hline 18 & 4 & 0 & 4 \\
\hline 19 & 2 & 0 & 2 \\
\hline 20 & 37 & 0 & 37 \\
\hline 21 & 0 & 9 & 9 \\
\hline 22 & 8 & 2 & 10 \\
\hline 23 & 25 & 15 & 40 \\
\hline 24 & 28 & 1 & 29 \\
\hline 25 & 2 & 1 & 3 \\
\hline 26 & 1 & 0 & 1 \\
\hline 27 & 10 & 0 & 10 \\
\hline 28 & 1 & 0 & 1 \\
\hline 29 & 0 & 38 & 38 \\
\hline 30 & 21 & 0 & 21 \\
\hline 31 & 28 & 0 & 28 \\
\hline 32 & 20 & 0 & 20 \\
\hline 33 & 51 & 0 & 51 \\
\hline 34 & 9 & 0 & 9 \\
\hline 35 & 13 & 0 & 13 \\
\hline 36 & 0 & 15 & 15 \\
\hline 37 & 9 & 0 & 9 \\
\hline 38 & 17 & 0 & 17 \\
\hline 39 & 14 & 7 & 21 \\
\hline 40 & 10 & 0 & 10 \\
\hline 41 & 63 & 17 & 80 \\
\hline 42 & 1 & 0 & 1 \\
\hline
\end{tabular}

TABLE E1. Continued

\begin{tabular}{|c|c|c|c|}
\hline Surgeon no. & ONCAB & ОРСАВ & Total \\
\hline 43 & 5 & 0 & 5 \\
\hline 44 & 1 & 47 & 48 \\
\hline 45 & 18 & 1 & 19 \\
\hline 46 & 2 & 0 & 2 \\
\hline 47 & 3 & 0 & 3 \\
\hline 48 & 5 & 16 & 21 \\
\hline 49 & 2 & 0 & 2 \\
\hline 50 & 26 & 0 & 26 \\
\hline 51 & 0 & 6 & 6 \\
\hline 52 & 4 & 0 & 4 \\
\hline 53 & 1 & 0 & 1 \\
\hline 54 & 0 & 6 & 6 \\
\hline 55 & 20 & 1 & 21 \\
\hline 56 & 22 & 0 & 22 \\
\hline 57 & 4 & 43 & 47 \\
\hline 58 & 29 & 0 & 29 \\
\hline 59 & 37 & 0 & 37 \\
\hline 60 & 5 & 0 & 5 \\
\hline 61 & 0 & 10 & 10 \\
\hline 62 & 0 & 6 & 6 \\
\hline 63 & 53 & 4 & 57 \\
\hline 64 & 1 & 0 & 1 \\
\hline 65 & 15 & 0 & 15 \\
\hline 66 & 1 & 0 & 1 \\
\hline 67 & 5 & 0 & 5 \\
\hline 68 & 6 & 9 & 15 \\
\hline 69 & 3 & 0 & 3 \\
\hline 70 & 0 & 1 & 1 \\
\hline 71 & 6 & 0 & 6 \\
\hline 72 & 11 & 0 & 11 \\
\hline 73 & 1 & 0 & 1 \\
\hline 74 & 17 & 1 & 18 \\
\hline 75 & 25 & 0 & 25 \\
\hline 76 & 0 & 3 & 3 \\
\hline 77 & 32 & 0 & 32 \\
\hline 78 & 1 & 0 & 1 \\
\hline 79 & 2 & 47 & 49 \\
\hline 80 & 1 & 0 & 1 \\
\hline 81 & 26 & 0 & 26 \\
\hline 82 & 6 & 0 & 6 \\
\hline 83 & 1 & 1 & 2 \\
\hline 84 & 0 & 1 & 1 \\
\hline 85 & 0 & 48 & 48 \\
\hline 86 & 1 & 77 & 78 \\
\hline 87 & 34 & 0 & 34 \\
\hline
\end{tabular}


TABLE E1. Continued

\begin{tabular}{|c|c|c|c|}
\hline Surgeon no. & ONCAB & ОРСAB & Total \\
\hline 88 & 37 & 0 & 37 \\
\hline 89 & 9 & 2 & 11 \\
\hline 90 & 1 & 0 & 1 \\
\hline 91 & 8 & 0 & 8 \\
\hline 92 & 3 & 0 & 3 \\
\hline 93 & 71 & 2 & 73 \\
\hline 94 & 7 & 2 & 9 \\
\hline 95 & 1 & 0 & 1 \\
\hline 96 & 13 & 0 & 13 \\
\hline 97 & 2 & 0 & 2 \\
\hline 98 & 1 & 34 & 35 \\
\hline 99 & 0 & 2 & 2 \\
\hline 100 & 1 & 0 & 1 \\
\hline 101 & 40 & 0 & 40 \\
\hline 102 & 1 & 0 & 1 \\
\hline 103 & 21 & 0 & 21 \\
\hline 104 & 27 & 8 & 35 \\
\hline 105 & 2 & 2 & 4 \\
\hline 106 & 31 & 2 & 33 \\
\hline 107 & 4 & 0 & 4 \\
\hline 108 & 6 & 12 & 18 \\
\hline 109 & 2 & 0 & 2 \\
\hline 110 & 11 & 20 & 31 \\
\hline 111 & 47 & 0 & 47 \\
\hline 112 & 0 & 3 & 3 \\
\hline 113 & 3 & 0 & 3 \\
\hline 114 & 1 & 0 & 1 \\
\hline 115 & 1 & 10 & 11 \\
\hline 116 & 1 & 0 & 1 \\
\hline 117 & 65 & 1 & 66 \\
\hline 118 & 1 & 0 & 1 \\
\hline 119 & 2 & 0 & 2 \\
\hline 120 & 18 & 5 & 23 \\
\hline 121 & 1 & 0 & 1 \\
\hline 122 & 26 & 5 & 31 \\
\hline 123 & 1 & 0 & 1 \\
\hline 124 & 1 & 8 & 9 \\
\hline 125 & 6 & 0 & 6 \\
\hline 126 & 1 & 0 & 1 \\
\hline 127 & 1 & 1 & 2 \\
\hline 128 & 6 & 0 & 6 \\
\hline 129 & 36 & 0 & 36 \\
\hline 130 & 5 & 1 & 6 \\
\hline 131 & 2 & 18 & 20 \\
\hline
\end{tabular}

\begin{tabular}{|c|c|c|c|}
\hline Surgeon no. & ONCAB & ОРСАВ & Total \\
\hline 132 & 1 & 0 & 1 \\
\hline 133 & 7 & 0 & 7 \\
\hline 134 & 4 & 0 & 4 \\
\hline 135 & 1 & 0 & 1 \\
\hline 136 & 0 & 1 & 1 \\
\hline 137 & 0 & 412 & 412 \\
\hline 138 & 1 & 0 & 1 \\
\hline 139 & 1 & 0 & 1 \\
\hline 140 & 29 & 0 & 29 \\
\hline 141 & 0 & 2 & 2 \\
\hline 142 & 2 & 0 & 2 \\
\hline 143 & 5 & 11 & 16 \\
\hline 144 & 1 & 0 & 1 \\
\hline 145 & 1 & 0 & 1 \\
\hline 146 & 17 & 0 & 17 \\
\hline 147 & 9 & 1 & 10 \\
\hline 148 & 1 & 0 & 1 \\
\hline 149 & 19 & 0 & 19 \\
\hline 150 & 5 & 0 & 5 \\
\hline 151 & 1 & 0 & 1 \\
\hline 152 & 1 & 0 & 1 \\
\hline 153 & 76 & 1 & 77 \\
\hline 154 & 30 & 179 & 209 \\
\hline 155 & 6 & 0 & 6 \\
\hline 156 & 1 & 0 & 1 \\
\hline
\end{tabular}


TABLE E2. Baseline characteristics in patients undergoing off-pump coronary artery bypass converted versus not converted to on-pump

\begin{tabular}{|c|c|c|c|}
\hline & OPCAB not converted & OPCAB converted to on-pump & $P$ value* \\
\hline $\mathrm{n}$ & 1231 & 29 & \\
\hline Age $(y)$ mean $(\mathrm{SD})$ & $63.59(9.06)$ & $64.40(9.77)$ & .634 \\
\hline Female, n (\%) & $179(14.5)$ & $1(3.4)$ & .16 \\
\hline BMI mean (SD) & $28.10(4.11)$ & $28.15(3.99)$ & .95 \\
\hline $\mathrm{SBP}(\mathrm{mm} \mathrm{Hg})$ mean $(\mathrm{SD})$ & $132.75(19.11)$ & $130.66(17.94)$ & .56 \\
\hline $\mathrm{DBP}(\mathrm{mm} \mathrm{Hg})$ mean $(\mathrm{SD})$ & $75.40(11.07)$ & $72.48(11.85)$ & .16 \\
\hline Creatinine (mmol/L) mean (SD) & $99.68(22.19)$ & $107.76(41.54)$ & .06 \\
\hline Treated hypertension, n (\%) & $919(74.7)$ & $24(82.8)$ & .44 \\
\hline Treated hyperlipemia, n (\%) & $1147(93.2)$ & $29(100.0)$ & .28 \\
\hline $\begin{array}{l}\text { Diabetes, } \mathrm{n}(\%) \\
\text { No } \\
\text { Insulin dependent } \\
\text { Noninsulin dependent }\end{array}$ & $\begin{array}{c}959(77.9) \\
68(5.5) \\
204(16.6)\end{array}$ & $\begin{array}{c}21(72.4) \\
2(6.9) \\
6(20.7)\end{array}$ & .78 \\
\hline $\begin{array}{l}\text { Smoking, n (\%) } \\
\text { Current } \\
\text { Ex-smoker } \\
\text { Never }\end{array}$ & $\begin{array}{l}173(14.1) \\
645(52.4) \\
413(33.5)\end{array}$ & $\begin{array}{r}7(24.1) \\
19(65.5) \\
3(10.3)\end{array}$ & .02 \\
\hline COPD, n (\%) & $29(2.4)$ & $0(0.0)$ & .83 \\
\hline Asthma, n (\%) & $58(4.7)$ & $5(17.2)$ & .009 \\
\hline PVD, n (\%) & $87(7.1)$ & $3(10.3)$ & .76 \\
\hline TIA, n (\%) & $40(3.2)$ & $0(0.0)$ & .65 \\
\hline CVA, n (\%) & $40(3.2)$ & $0(0.0)$ & .65 \\
\hline MI, n (\%) & $493(40.0)$ & $17(58.6)$ & .07 \\
\hline PCI, n (\%) & $199(16.2)$ & $9(31.0)$ & .06 \\
\hline Preoperative AF, n (\%) & $18(1.5)$ & $1(3.4)$ & .92 \\
\hline $\begin{array}{l}\text { Preoperative LVEF }(\%) \\
\quad \geq 50 \% \text { (good) } \\
31 \%-49 \% \text { (moderate) } \\
\leq 30 \% \text { (poor) }\end{array}$ & $\begin{array}{c}927(75.3) \\
264(21.4) \\
40(3.2)\end{array}$ & $\begin{array}{c}23(79.3) \\
4(13.8) \\
2(6.9)\end{array}$ & .37 \\
\hline LMD, n (\%) & $276(22.4)$ & $6(20.7)$ & 1 \\
\hline RA, n (\%) & $231(18.8)$ & $9(31.0)$ & .15 \\
\hline SVG, n (\%) & $916(74.4)$ & $20(69.0)$ & .65 \\
\hline BITA, n (\%) & $582(47.3)$ & $16(55.2)$ & .51 \\
\hline
\end{tabular}

$O P C A B$, Off-pump coronary artery bypass; $S D$, standard deviation; $B M I$, body mass index; $S B P$, systolic blood pressure; $D B P$, diastolic blood pressure; $C O P D$, chronic obstructive pulmonary disease; $P V D$, peripheral vascular disease; $T I A$, transient ischemic attack; $C V A$, cerebrovascular accident; $M I$, myocardial infarction; $P C I$, percutaneous coronary intervention; $A F$, atrial fibrillation; $L V E F$, left ventricular ejection fraction; $L M D$, left main disease; $R A$, radial artery; $S V G$, saphenous vein graft; $B I T A$, bilateral internal thoracic artery. *Chi-square test or $t$ test. 
TABLE E3. Baseline characteristics of off-pump coronary artery bypass and matched on-pump coronary artery bypass patients stratified for surgeon trial off-pump coronary artery bypass volume

\begin{tabular}{|c|c|c|c|c|c|c|c|c|}
\hline \multirow[b]{2}{*}{ Surgeon trial OPCAB volume quartiles } & \multicolumn{4}{|c|}{ Matched ONCAB } & \multicolumn{4}{|c|}{ ОРСАВ } \\
\hline & 0 & $1-5$ & $6-60$ & $>60$ & 0 & $1-5$ & $6-60$ & $>60$ \\
\hline No. of surgeons & 95 & 33 & 25 & 3 & 95 & 33 & 25 & 3 \\
\hline No. of patients & 688 & 340 & 204 & 28 & - & 62 & 530 & 668 \\
\hline Age $(y)$ mean $(\mathrm{SD})$ & $64(9)$ & $62(9)$ & $6(9)$ & $66(9)$ & - & $64(8)$ & $62(8)$ & $65(9)$ \\
\hline Female, n (\%) & $93(13.5)$ & $55(16.2)$ & $28(13.7)$ & $4(14.3)$ & - & $7(11.3)$ & $55(10.4)$ & $118(17.7)$ \\
\hline BMI mean (SD) & $28(4)$ & $28(4)$ & $28(4)$ & $29(4)$ & - & $27(4)$ & $28(4)$ & $28(4)$ \\
\hline $\mathrm{SBP}(\mathrm{mm} \mathrm{Hg})$ mean $(\mathrm{SD})$ & $133(17)$ & $132(17)$ & $133(21)$ & $134(15)$ & - & $132(17)$ & $131(19)$ & $134(20)$ \\
\hline $\mathrm{DBP}(\mathrm{mm} \mathrm{Hg})$ mean $(\mathrm{SD})$ & $75.50(11.51)$ & $74.91(10.99)$ & $75.22(11.02)$ & $72.72(13.01)$ & - & $75.11(8.85)$ & $76.51(10.96)$ & $74.42(11.30)$ \\
\hline Creatinine $(\mathrm{mmol} / \mathrm{L})$ mean $(\mathrm{SD})$ & $98(23)$ & $95(20)$ & $101(19)$ & $111(17)$ & - & $94(31)$ & $96(22)$ & $104(22)$ \\
\hline Treated hypertension, $\mathrm{n}(\%)$ & $508(73.8)$ & $272(80.0)$ & $146(71.6)$ & $24(85.7)$ & - & $53(85.5)$ & $389(73.4)$ & $501(75.0)$ \\
\hline Treated hyperlipemia, n (\%) & $629(91.4)$ & $323(95.0)$ & $201(98.5)$ & $25(89.3)$ & - & $59(95.2)$ & $516(97.4)$ & $601(90.0)$ \\
\hline Diabetes n $(\%)$ & & & & & - & & & \\
\hline No & $540(78.5)$ & $257(75.6)$ & $163(79.9)$ & $23(82.1)$ & - & $49(79.0)$ & $415(78.3)$ & $516(77.2)$ \\
\hline Insulin dependent & $28(4.1)$ & $24(7.1)$ & $13(6.4)$ & $2(7.1)$ & - & $2(3.2)$ & $25(4.7)$ & $43(6.4)$ \\
\hline Noninsulin dependent & $120(17.4)$ & $59(17.4)$ & $28(13.7)$ & $3(10.7)$ & - & $11(17.7)$ & $90(17.0)$ & $109(16.3)$ \\
\hline Smoking, $\mathrm{n}(\%)$ & & & & & - & & & \\
\hline Current & $78(11.3)$ & $50(14.7)$ & $18(8.8)$ & $3(10.7)$ & - & 8 (12.9) & $85(16.0)$ & 87 (13.0) \\
\hline Ex-smoker & $384(55.8)$ & $196(57.6)$ & $131(64.2)$ & $12(42.9)$ & - & $37(59.7)$ & $264(49.8)$ & $363(54.3)$ \\
\hline Never & $226(32.8)$ & 94 (27.6) & $55(27.0)$ & $13(46.4)$ & - & $17(27.4)$ & $181(34.2)$ & 218 (32.6) \\
\hline COPD, n $(\%)$ & $14(2.0)$ & $6(1.8)$ & $8(3.9)$ & $0(0.0)$ & - & $1(1.6)$ & $11(2.1)$ & $17(2.5)$ \\
\hline Asthma, n (\%) & $35(5.1)$ & $11(3.2)$ & $11(5.4)$ & $2(7.1)$ & - & $2(3.2)$ & $24(4.5)$ & $37(5.5)$ \\
\hline PVD, n (\%) & $45(6.5)$ & $20(5.9)$ & $14(6.9)$ & $2(7.1)$ & - & $2(3.2)$ & $29(5.5)$ & $59(8.8)$ \\
\hline TIA, n (\%) & $18(2.6)$ & $10(2.9)$ & $11(5.4)$ & $1(3.6)$ & - & $1(1.6)$ & $19(3.6)$ & $20(3.0)$ \\
\hline CVA, n (\%) & $28(4.1)$ & $7(2.1)$ & $3(1.5)$ & $0(0.0)$ & - & $1(1.6)$ & $11(2.1)$ & $28(4.2)$ \\
\hline MI, n (\%) & $272(39.5)$ & $148(43.5)$ & 81 (39.7) & $12(42.9)$ & - & $28(45.2)$ & $226(42.6)$ & $256(38.3)$ \\
\hline PCI, n (\%) & $102(14.8)$ & $63(18.5)$ & $46(22.5)$ & $3(10.7)$ & - & $17(27.4)$ & $135(25.5)$ & $56(8.4)$ \\
\hline Preoperative AF, n (\%) & $8(1.2)$ & $3(0.9)$ & $5(2.5)$ & $0(0.0)$ & - & $0(0.0)$ & $7(1.3)$ & $12(1.8)$ \\
\hline Preoperative LVEF $(\%)$ & & & & & - & & & \\
\hline$\geq 50 \%$ (good) & $516(75.0)$ & $253(74.4)$ & $153(75.0)$ & $17(60.7)$ & - & $52(83.9)$ & $405(76.4)$ & $493(73.8)$ \\
\hline $31 \%-49 \%$ (moderate) & $162(23.5)$ & $85(25.0)$ & $48(23.5)$ & $8(28.6)$ & - & $10(16.1)$ & $112(21.1)$ & $146(21.9)$ \\
\hline$\leq 30 \%$ (poor) & $10(1.5)$ & $2(0.6)$ & $3(1.5)$ & $3(10.7)$ & - & $0(0.0)$ & $13(2.5)$ & $29(4.3)$ \\
\hline LMD, n (\%) & 149 (21.7) & $85(25.0)$ & $34(16.7)$ & $9(32.1)$ & - & $6(9.7)$ & $101(19.1)$ & $175(26.2)$ \\
\hline $\mathrm{RA}, \mathrm{n}(\%)$ & $137(19.9)$ & $84(24.7)$ & $27(13.2)$ & $4(14.3)$ & - & $9(14.5)$ & $90(17.0)$ & $141(21.1)$ \\
\hline SVG, n (\%) & $524(76.2)$ & $232(68.2)$ & $175(85.8)$ & $25(89.3)$ & - & $38(61.3)$ & $400(75.5)$ & $498(74.6)$ \\
\hline BITA, n (\%) & $308(44.8)$ & $171(50.3)$ & $85(41.7)$ & $11(39.3)$ & - & $23(37.1)$ & $252(47.5)$ & $323(48.4)$ \\
\hline
\end{tabular}

$O N C A B$, On-pump coronary artery bypass; $O P C A B$, off-pump coronary artery bypass; $S D$, standard deviation; $B M I$, body mass index; $S B P$, systolic blood pressure; $D B P$, diastolic blood pressure; $C O P D$, chronic obstructive pulmonary disease; $P V D$, peripheral vascular disease; $T I A$, transient ischemic attack; $C V A$, cerebrovascular accident; $M I$, myocardial infarction; $P C I$, percutaneous coronary intervention; $A F$, atrial fibrillation; $L V E F$, left ventricular ejection fraction; $L M D$, left main disease; $R A$, radial artery; $S V G$, saphenous vein graft; BITA, bilateral internal thoracic artery. 
TABLE E4. Outcomes in patients undergoing off-pump coronary artery bypass converted versus not converted to on-pump

\begin{tabular}{|c|c|c|c|}
\hline & OPCAB converted to on-pump & OPCAB not converted & $P$ value \\
\hline $\mathrm{N}$ & 29 & 1231 & \\
\hline \multicolumn{4}{|l|}{ In-hospital outcomes* } \\
\hline Death, n (\%) & $3(10.3)$ & $9(0.7)$ & $<.001$ \\
\hline CVA, n (\%) & $1(3.4)$ & $19(1.5)$ & .95 \\
\hline MI, n (\%) & $0(0.0)$ & $10(0.8)$ & 1 \\
\hline CK-MB at $24 \mathrm{~h}(\mathrm{U} / \mathrm{L})$ mean (SD) & $182(102)$ & $31(179)$ & .15 \\
\hline IABP insertion, $\mathrm{n}(\%)$ & $10(34.5)$ & $48(3.9)$ & $<.001$ \\
\hline Repeat revascularization, $\mathrm{n}(\%)$ & $1(3.4)$ & $7(0.6)$ & .46 \\
\hline POAF, n (\%) & $15(51.7)$ & $264(21.4)$ & $<.001$ \\
\hline Renal replacement therapy, n (\%) & $4(13.8)$ & $68(5.5)$ & .14 \\
\hline AKI, n (\%) & $16(55.2)$ & $209(17.0)$ & $<.001$ \\
\hline Sternal wound complication, n (\%) & $1(3.4)$ & $34(2.8)$ & 1 \\
\hline Reexploration for bleeding, $\mathrm{n}(\%)$ & $3(10.3)$ & $37(3.0)$ & .09 \\
\hline RBC transfusion, $\mathrm{n}(\%)$ & $17(58.6)$ & $148(12.0)$ & $<.001$ \\
\hline \multicolumn{4}{|l|}{ 5-y outcomes $\dagger$} \\
\hline Mortality, n (\%) & $4(13.8)$ & $106(8.8)$ & .3 \\
\hline MACCE, n (\%) & $8(27.9)$ & $167(14.0)$ & .02 \\
\hline $\mathrm{CV}$ death, $\mathrm{n}(\%)$ & $3(10)$ & $48(4.0)$ & .08 \\
\hline MI, n (\%) & $2(6.9)$ & 35 (2.9) & .18 \\
\hline CVA, n (\%) & $1(3.4)$ & $40(3.3)$ & .92 \\
\hline Repeat revascularization & $4(13.8)$ & $86(7.1)$ & .12 \\
\hline
\end{tabular}

$O P C A B$, Off-pump coronary artery bypass; $C V A$, cerebrovascular accident; $M I$, myocardial infarction; $C K-M B$, creatine kinase-MB; $S D$, standard deviation; $I A B P$, intra-aortic balloon pump; $P O A F$, postoperative atrial fibrillation; $A K I$, Acute kidney injury; $R B C$, red blood cell; $M A C C E$, major cardiac and cerebrovascular event; $C V$, Cardiovascular. *Chi-square test or $t$ test. †Cox regression model.

TABLE E5. Outcomes among off-pump coronary artery bypass and matched on-pump coronary artery bypass patients stratified for surgeon trial off-pump coronary artery bypass volume

\begin{tabular}{|c|c|c|c|c|c|c|c|c|}
\hline \multirow[b]{2}{*}{$\begin{array}{l}\text { Surgeon trial OPCAB volume } \\
\text { quartiles }\end{array}$} & \multicolumn{4}{|c|}{ Matched ONCAB } & \multicolumn{4}{|c|}{ ОРСАВ } \\
\hline & 0 & $1-5$ & $6-60$ & $>60$ & 0 & $1-5$ & $6-60$ & $>60$ \\
\hline No. of surgeons & 95 & 33 & 25 & 3 & 95 & 33 & 25 & 3 \\
\hline No. of patients & 688 & 340 & 204 & 28 & - & 62 & 530 & 668 \\
\hline Hospital death, n (\%) & $8(1.2)$ & $4(1.2)$ & $1(0.5)$ & $2(7.1)$ & - & $3(4.8)$ & $3(0.6)$ & $6(0.9)$ \\
\hline Conversion rate, $\mathrm{n}(\%)$ & - & - & - & - & - & $8(12.9)$ & $14(2.6)$ & $7(1.0)$ \\
\hline No. of grafts mean (SD) & $3.14(0.77)$ & $3.12(0.78)$ & $3.31(0.72)$ & $3.43(0.57)$ & - & $2.60(0.88)$ & $3.20(0.85)$ & $3.26(0.87)$ \\
\hline 5-y mortality, n (\%) & $65(9.6)$ & $22(6.7)$ & $10(4.9)$ & $5(17.9)$ & - & $5(8.2)$ & $40(7.8)$ & $65(9.9)$ \\
\hline 5-y MACCE, n (\%) & $94(14.0)$ & $44(13.4)$ & 24 (11.9) & $7(25.7)$ & - & $9(14.9)$ & $52(10.2)$ & $114(17.5)$ \\
\hline 5-y CV death, n (\%) & $23(3.4)$ & $8(2.4)$ & $4(2.0)$ & $28(14.3)$ & - & $3(4.8)$ & $15(2.9)$ & $33(5.0)$ \\
\hline 5-y MI, n (\%) & $23(3.4)$ & $19(5.6)$ & $8(3.9)$ & $1(3.6)$ & - & $3(4.8)$ & $9(1.7)$ & $25(3.8)$ \\
\hline 5-y CVA, n (\%) & $16(2.4)$ & $8(2.4)$ & $6(3.0)$ & $2(7.1)$ & - & $2(3.3)$ & $16(3.1)$ & $23(3.5)$ \\
\hline 5 -y revascularization, $\mathrm{n}(\%)$ & $52(7.7)$ & $16(4.9)$ & $14(6.9)$ & $28(7.1)$ & - & $3(5.0)$ & $23(4.5)$ & $64(9.7)$ \\
\hline
\end{tabular}

$O N C A B$, On-pump coronary artery bypass; $O P C A B$, off-pump coronary artery bypass; $S D$, standard deviation; $M A C C E$, major cardiac and cerebrovascular event; $C V$, cardiovascular; $M I$, myocardial infarction; $C V A$, cerebrovascular accident. 